\title{
Curriculum Development and Dermatology Training
}

\author{
Betkerur J \\ Professor, Dept of Dermatology, Venereology and Leprosy, JSS Medical College and Hospital.
}

\author{
Address for correspondence \\ Dr. Jayadev Betkerur, MD \\ Professor \\ Department of Dermatology Venerology \& Leprosy \\ JSS Medical College \& Hospital \\ JSS University, Mysuru, India. \\ Phone no : +91 9448270612 \\ E-mail : jbetkerur@gmail.com
}

\begin{abstract}
Curriculum is an integral part of any educational cycle. Curriculum development is a systematic process involving designing, implementing, evaluating and redesigning. There are different types of curriculums being practiced by institutions. Subject based curriculum is a widely used but competency based curriculum is the best. There is an urgent need to have relook at the existing curriculum as it is beset with many problems. The faculty development (FD) is one factor affecting curriculum development. We need to identify the other issues and address them.

Presently Dermatology postgraduate training is more concentrated in imparting more knowledge based learning. Acquiring and assessing skills not included in the program.The curriculum is decades old and does not address the present needs. The classification of diseases can be modified. Evaluation methods have to be structured to assess knowledge and skill. Dermatosurgery, dermatotherapeutics and cosmetic dermatology needs to be added to the curriculum. The teachers, institutions and regulatory authorities to plan strategies to bring about these changes to present to the society a knowledgeable, skillfull, sensitive and ethically correct.
\end{abstract}

Key words: Curriculum development, faculty development, dermatology curriculum.

\section{Introduction}

$\mathrm{C}$ urriculum development is an integral part of medical education. Since decades it has seen no changes. The lack of this has resulted in a more knowledge oriented medical education. We the teachers, institutions and regulatory authorities have to identify defects and take remedial actions.

Post graduate dermatology training is also suffering from the same malady. A review at the dermatology curriculum is urgently warranted. This article tries to look at the present status of curriculum in both medicine in general and dermatology in particular and discuss the possible means to improve effect changes in dermatology curriculum.

The education system is an ever evolving process and this process is called the Educational cycle. The educational cycle is a dynamic cycle consisting of 4 components to achieve the target of competency in that subject. The components are curriculum development, training, assessment and gap analysis. When done systematically the educational system can be improved to fulfill the present needs. Curriculum is an essential part of educational cycle.

Curriculum is defined as "A course of study offered by an educational institute". It is the foundation of every educational system. The curriculum needs to be developed by systematically organizing what will be taught, who will be taught, and how it will be taught. Each component affects and interacts with other components. Methods of how content is taught are affected by who is being taught, their characteristics, and the setting. According to the model of Kern et al for curriculum development in medical education, the first steps are identifying the problem and performing a need assessment. Need assessment is defined as the difference between the ideal approach of addressing an identified need and the current approach. ${ }^{1}$

There are six essential considerations while developing a curriculum for any course. They are :- 
1. Identification of the issue- which is what to teach.

2. Know the character of the learner - that is the who

3. The importance and relevance of the content.

4. The expected outcome.

5. The best methods to make the learner achieve the goal - The how of it.

6. Developing methods to evaluate the work done so that lacunas can be identified and the system is improved.

Simply put there needs to be a goal or an objective to achieve which should be taught using effective teaching methods and evaluated periodically. Curriculum development requires team work. The team discusses the issue, collects the data about the existing system. A single system is selected, alterations are made according to local needs considering the cultural, social and disease diversity. The team then systematically analyses the learner's characters, intended outcome, content and evaluation methods before implementing. The designed curriculum is either implemented as a pilot project or fully. This is monitored throughout the course. Evaluation is done using effective measureable methods. If satisfactory the curriculum is implemented or redesigned as required. This is also called the ADDIE model- Analysis, Design, Development, Implementation and Evaluation.

One of the very essential parts of curriculum development is to have an effective Instructional Design (ID). Here instruction is the thing that helps one to learn and design is that which improves the quality of that help. The ID can be behavioral approach or cognitive approach. In Behavioural Approach the theorist expects to achieve immediate, recognizable changes in the behaviour by framing instructional goals in specific, behavioural, observable terms. In Cognitive Approach learners build their own understanding based on their unique experience. Here, the instructional goals are framed in empirical terms, thereby proposing the learner problems, learner control over the environment, activities to be engaged and how these activities can be shaped by the instructor. $^{2}$

Types of curriculum: There are 5 types of curriculum followed by various institutions:-

1. Subject based - Perhaps is the most widely practiced all over. It is a scientific, evidence based and time tested curriculum. Unfortunately there is disconnect between what is taught and what should have been learnt. There is no direct contact with patients and often exposure to unusual cases rather than common

2. Integrated-Here independent disciplines like the Scientific and clinical discipline are fused to make learning meaningful. It is a pure independent discipline. This core curriculum is under evaluation.

3. Competence based - This probably is the best curriculum structured around competency. The aim is to produce a graduate who responds to local needs. The student is allowed to master basic performance objective. The emphasis in on how much the learner knows and also how he performs. Education an experiment. In the discipline of medicine it is called Competency Based Medical Education (CBME).The important aspect of this curriculum is competence, which is easily measureable hence can be assessed regarding its quality of acquisition. However implementing this requires new skills for teacher -i.e faculty development.

It is pertinent here to define competence "Competency is an observable ability of health professional, integrating multiple components such as knowledge, skills, values and attitudes. Since competencies are observable they can be measured and assessed to assure their acquisition. Competencies can be assembled like building blocks to facilitate progressive development."

The advantages of Competency based education are a) It clarifies what is important and makes performance expectations more explicit in Competency-based postgraduate medical education (PGME). It is unlikely that will be gained through the increased use or implementation of competency-based approaches in residency education lead to faster completion of PGME. However, with the additional focusing on learning, teaching and assessment, it will be easier to overcome the current challenges to meet the training requirements. b) Competency -based approaches illustrate the need for enhanced assessment practices and tools c) competency based PGME would benefit integrating a competency-based model that includes explicit expectations and assessment yet being cautious and avoiding the risk of deconstruction of practice into ever smaller units of competence or of focusing on only those competencies that are easy to describe and assess ${ }^{3}$

1. Hybrid Blend of face to face in class teaching with web based teaching such as online course, discussion board etc.

\section{Problem based}




\section{Where are we in Post Graduate Medical Curriculum}

"The medical curriculum needs to look at developing a doctor who is trained to look at health in holistic manner which goes beyond a narrow clinical and technology driven education. The doctors should be technically competent, socially sensitive, ethically correct and respond to diverse demands of our health needs. Hence there is an urgent need to look afresh at our curriculum". Dr. Manmohan Singh, Former Prime minister of India.

The realization that medical graduates are failing to serve the health needs of the society has compelled the medical educationists and regulatory authorities worldwide to review the medical training. A medical curriculum oriented towards developing the key competencies that enable a fresh graduate to be delivering socially responsive health care is seen as a promising step towards alleviating this problem. This calls for a departure from the traditional approach of organizing the curricular components around educational objectives, to a competency-based approach for planning the curriculum. ${ }^{4}$

Any limitations in implementing change in postgraduate medical education will likely result from a lack of imagination in those planning postgraduate medical education and their inability to bring about the necessary changes. To avoid a growing gap developing between what is possible educationally and what is delivered, it is clear that we need a new paradigm for postgraduate medical education. ${ }^{5}$ In the future the post graduate education should develop in to a more need based training to cater to the need of population, the course becomes more flexible depending on the learners capabilities, more technology enhanced with emphasis on life long learning. The training needs to be value for money as training is expensive and it will be more personalized with continuous clinical and educational supervision in the early years and greater freedom in the last year of training. ${ }^{6}$ An enormous shortage of medical teachers exists and the shortage is expected to increase in the future in view of the rise in the number of medical colleges. Poor training in research methodology is a hallmark of the current PG system, although PGs spend a considerable part of their time preparing a research dissertation as per the requirements. The level of skills is also unsatisfactory since the curriculum does not lay much emphasis on the development of skills, being primarily oriented to the acquisition of knowledge. ${ }^{7} A$ teacher plays an important role in improving and implementing curriculum. Teacher should act as an information provider in the lecture, in the clinical context, role model on-the-job, and in more formal teaching settings learning facilitator. The role also includes as student assessor, resource material creator, and study guide producer. He or she need to plan the curriculum and course and evaluate them periodically. ${ }^{8}$

Faculty Development (FD) is one of the most important aspect in improving curriculum and achieving our goal. Many institutions have initiated FD programs through Medical education Units (MEU) which is mandatory for $\mathrm{MCl}$ recognition in India.

\section{What is faculty development?}

FD is a planned program (i) to improve an individual's knowledge and skills in teaching, educational research and educational administration and (ii) to prepare institution and faculty members for their various roles. In medical education, faculty development deals with the sensitization and training of teachers in carrying out their professional tasks, which lead to improvement in the quality of teaching and learning that contributes to the competence of health professionals.. The theme of faculty development is how best to sensitize, equip and empower teachers for discharging their professional responsibilities.

\section{Why faculty development is needed in medical education?}

Teaching is a demanding and complex task. George Miller observed, "It is curious that so many of our most important responsibilities are undertaken without significant preparation. Marriage, parenthood and teaching (in medical schools) are probably most ubiquitous illustrations". It is necessary for the present day teacher to be aware of and become part of far reaching changes that are taking place in medical education.

\section{Problems with faculty development}

As observed above there is acute shortage of teachers. There is no well-developed FD policy by the regulating authorities, however there is belated realization of this and measures have been taken in this regard at institution, University and government level. Majority of teachers are not motivated as the incentives are meager. Resource deficiency for FD is another major hindrance. The recommendations are, provide financial support for undergoing FD. Recognition and encouragement to implement what has been learnt, 
incorporate medical educational techniques in PG training. It is important to have functional MEUs in medical colleges. ${ }^{9}$

\section{Curriculum Development for Post Graduate (PG) training in dermatology}

Dermatology is a vast subject incorporating other two very important branches, Venereology and Leprosy. The latter two are prevalent in this part of the world and are of public health importance. With advances in Dermatotherapeutics, Dermatosurgery, Cosmetology and Aesthetic Dermatology there is heightened interest among medical graduates to pursue postgraduation in Dermatology. Hence we need to look at existing dermatology curriculum, identify lacunas and suggest remedial measures.

The aim of Dermatology training should be to formulate the Minimum Required Knowledge (MRK) in each areas of dermatology. There is lack of defined boundaries of minimal knowledge regarding each desired aspect of learning according to different levels of achievements. Nowhere the required minimum knowledge is quantified for different levels. In present era of exponential growth of knowledge in each subject, it has become more important to draw the frontiers of MRK about each desired aspect of learning according to level of achievement. ${ }^{10}$

Presently the dermatology curriculum is beset with many problems :-

1. There is no uniformity in curriculum or teaching.

2. There are no guidelines as to what extent a topic in dermatology is to be taught and how to teach.

3. The curriculum is decades old.

4. It is a subject based curriculum with more emphasis on knowledge than skill.

5. Shortage of trained teachers.

6. Limited or no research work

7. The PG's are not given opportunity to teach undergraduates.

8. Evaluation methods are almost obsolete.

9. No weight age for internal assessment

The above factors have made dermatology learning difficult. The students and faculty are confused as to what to teach and learn. Most dermatology departments are not equipped to provide a training program which can produce a knowledgeable and skilled dermatologist.

\section{Measures for improvement}

Many people have worked on tackling these lacunas and have suggested various methods. The suggested measures.

1. Subject needs to be divided into must know, should know and good or desirable to know.

2. Teaching should be towards developing clinical, diagnostic, surgical and dermatopathology skills than just the knowledge about the subject.

3. Teaching and learning methods need to be changed.

4. Emphasis to be laid on developing and conducting research projects, both basic and community based. ${ }^{11}$

5. Post graduate should be mandatorily posted in related subjects on rotation basis.

6. Sub specialties of dermatology needs to be given importance. But not over emphasized.

7. Include under graduate teaching in PG curriculum and encourage PG's to take up teaching.

8. Evolve and encourage development of newer teaching techniques.

9. Evaluation should be made formative than summative. The evaluation is still based on theoretical and clinical knowledge. Many newer evaluation methods have been suggested and are being implemented in many universities. (Table 1 )

Dermatology training consists of case discussion both in outpatient and wards. Each disease in itself carries an unlimited universe of knowledge. This includes epidemiology, etiology, genetics, pathogenesis, available investigations, variation in differential diagnosis according to clinical presentations, recent therapeutic advances in the light of evidence based medicine. A student becomes totally perplexed when he is confronted with so varied aspects and that too without any defined limitation. ${ }^{10}$

Rehanuddin et al $^{10}$ suggested a review classification of skin diseases according to prevalence and treatability of the condition. This classification is devised in contrast to existing classification used in both local and international literature which is either system based or according to etiology. The points of concerns in classifying diseases is that both trainers and examiners neglect common and treatable conditions and students remain entangled in complex, confusing and untreatable conditions. (Table1)

The focus of student assessment has shifted to the use of multiple-methods for testing a wide gamut of 
learning outcomes, such as higher cognitive abilities, communication skills, IT skills and professionalism including ethical behavior. Many of the methods lay emphasis on frequent assessment of learning outcomes through predetermined agreed assessment criteria, using observation check- lists, or rating scales for scoring. It is, therefore, essential for our teachers to be aware of these new developments and suitably adopt them in our medical education system. Trends in dermatology resident learning style preferences should be considered during curriculum development. Programs should integrate a variety of curriculum delivery methods to accommodate various learning styles, with an emphasis on the active learning styles preferred by residents. ${ }^{12}$ Although lectures are perhaps the most common way to present knowledge in the medical setting, there is mounting evidence that didactic teaching is inferior to active learning methods that target distinct types of learning (cognitive, affective, and psychomotor learning). Many teaching strategies have been used in inpatient settings, including lectures, bedside teaching, skills sessions, quizzes, and online modules, with mixed results of tolerability and efficacy.We propose that specialists use consults as a proxy for needs assessment for developing relevant curriculum, and should perform critical assessment of current teaching methods to deliver knowledge that measurably improves physician performance and patient care. There is need for inpatient dermatology services and a need for novel methods to teach dermatology to hospitalists. ${ }^{13} \mathrm{~A}$ study among dermatology residents showed that they desired more teaching (clinic, didactic, and practice management) and mentorship from their faculty. Residents were most satisfied with dermatopathology education and least satisfied with cosmetic dermatology and dermoscopy training. In reality, in the subcontinent, cosmetology and aesthetic dermatology take precedence. During residency men indicated more interest than women in academics, research, and teaching, while female residents were more inclined toward pediatric dermatology and cosmetic dermatology. An overall trend of decreased interest in academic and hospital-based practice was noted with progression through residency training. Recruitment and retention of women in academic dermatology may benefit from early intervention ${ }^{14} \mathrm{~A}$ curriculum including an approach to molecular diagnostics testing, which could become integral to the practice of dermatology should be developed. ${ }^{15}$ Adding teledermatology as part of curriculum in Dermatology PG training, specially for out patient consultation is also a need. ${ }^{16}$

There is also a suggestion that Dermatology can be a full time training (FTT) where Core medical training in Medicine and related Dermatology training is imparted or less than full time training (LTFT) here the training is to formulate the minimum required knowledge (MRK) in each area of dermatology. Lack of guidelines as to what extent a topic in dermatology is to be taught and how to deliver are the main concerns in the implementation of these two training programmes.

Majority of the curriculum changes are often abandoned largely because of the institutions failure to make changes in structure and function that will support and promote dynamic process of curriculum development (Tyler 1970)

To conclude there is an urgent need to develop a country wide uniform Dermatology Curriculum so that a competent, skilled and knowledgeable dermatologist is presented to the community.

Table 1: Evaluation methods

\begin{tabular}{|l|l|}
\hline Theory & Practical \\
\hline & Case presentation \\
& OSLER(objective structured long examination record) \\
OSCE \& OSPE & Mini CEX(mini case evaluation exercise) \\
Short structured essay question (SEQs). & CbD(case based discussion) \\
Modified essay questions( MEQ's) & DOPs(Direct observation of procedures) \\
Patient management problems (PMPs) & Port folio \\
MCQs & Multi source- feed back \\
& 360 degrees \\
\hline Internal assessment to be considered for final result. & Patient satisfaction questionnaire \\
\hline
\end{tabular}


Table 2: Proposed classification of skin diseases developed for postgraduate curriculum of dermatology ${ }^{10}$

\begin{tabular}{|c|l|l|}
\hline Groups & Criterion & Examples of diseases \\
\hline Group 1 & Very common curable problems & $\begin{array}{l}\text { Acne, infections (scabies, wart, chickenpox, herpes } \\
\text { zoster and simplex, fungal, and bacterial infections) } \\
\text { dermatitis, pruritus, and drug eruption }\end{array}$ \\
\hline Group2 & $\begin{array}{l}\text { Common problems with unusual } \\
\text { presentation }\end{array}$ & Severe acne, Severe drug reactions, Crusted scabies \\
\hline Group 3 & Uncommon curable problems & Skin tuberculosis, leprosy, syphilis, leishmaniasis \\
\hline Group 4 & $\begin{array}{l}\text { Common incurable but manageable } \\
\text { problems }\end{array}$ & $\begin{array}{l}\text { Psoriasis, Lichen planus, Connective tissue disorders, } \\
\text { Blistering disorders, Tumours, Vasculitides }\end{array}$ \\
\hline Group 5 & Uncommon but manageable problems & Skin tumours both benign and malignant \\
\hline Group 6 & $\begin{array}{l}\text { Common but unmanageable and } \\
\text { untreatable problems }\end{array}$ & $\begin{array}{l}\text { Pigmentary disorders, Certain birthmarks, Congenital } \\
\text { defects }\end{array}$ \\
\hline Group 7 & Rare problems but manageable & Rare infections \\
\hline Group 8 & Rare and untreatable/unmanageable & $\begin{array}{l}\text { Hereditary defects } \\
\text { Very rare syndromes }\end{array}$ \\
\hline
\end{tabular}

\section{References}

1. Kern D, Thomas P, Hughes M. Curriculum development for medical education: a six step approach. Baltimore (MD): Johns Hopkins University Press; 1998.

2. Siribaddana P. The future of Instructional Designing in Medical Education : Letting the computer do the work. Sri Laanka Journal of Bio Medical Informatics 2010; 1(1): 76-85. https:// doi.org/10.4038/sljbmi.v1i1.1488

3. Glover Takahashi S, Waddell A, Kennedy $M$, Hodges B. Innovations, Integration and Implementation Issues in Competency-Based Training in Postgraduate Medical Education. Members of the FMEC PG consortium; 2011.

4. Modi JN, Gupta P, Singh T. Competencybased Medical Education, Entrustment and Assessment. Indian Pediatr. 2015; 52(5): 41320. https://doi.org/10.1007/s13312-015-06475

5. Harden RM. Trends and the future of postgraduate medical education. Emerg Med J. 2006; 23(10): 798-802. https://doi. org/10.1136/emj.2005.033738

6. Walsh $\mathrm{K}$. The future of postgraduate training. Pan Afr Med J. 2014; 19: 333. https://doi. org/10.11604/pamj.2014.19.333.5555

7. Ananthakrishnan N. Is there a need for transformational change to overcome the current problems with postgraduate medical education in India? Natl Med J India 2012; 25: 101-8.
8. Harden RM, Crosby JR. The good teacher is more than a lecturer - the twelve roles of teacher. AMEE Education Guide 2000; 22(4): 334-47.

9. Srinivas DK, Adkoli BV. Faculty Development in Medical Education in India: The need of the day. Al Ameen J med Sci 2009; 2 (1): 6-13.

10. Rehanuddin, Rizvi SD. A problem of being trainer and examiner of dermatology. J Pak Asso of Derm 2011; 21(3): 137- 40.

11. Pawar $A B$. Need for intensive training on research methodology in Medical Education. National J Community Medicine 2011; 2(2): 179-80.

12. Stratman EJ, Vogel CA, Reck SJ, Mukesh BN. Analysis of dermatology resident self-reported successful learning styles and implications for core competency curriculum development. Med Teach. 2008; 30(4): 420-5. https://doi. org/10.1080/01421590801946988.

13. Beshay A, Liu M, BS, Fox L, Shinkai K. Inpatient dermatology consultative programs: A continued need, tools for needs assessment for curriculum development, and a call for new methods of teaching. J Am Acad Dermatol 2016; 74: 769-71. https://doi.org/10.1016/j. jaad.2015.11.017.

14. Freiman A, Barzilai DA, Barankin B, Natsheh A, Shear NH. National appraisal of dermatology residency training: a Canadian study. Arch Dermatol. 2005; 141(9): 1100-4. https://doi.org/10.1001/archderm.141.9.1100 
15. Murphy MJ, Shahriari N, Payette $M$, Mnayer L, Elaba Z. Development of a curriculum in molecular diagnostics, genomics and personalized medicine for dermatology trainees. J Cutan Pathol. 2016; 43(10): 858-65. https://doi. org/10.1111/cup.12760
16. PatelJ,ParrK, Buehler-BotaT,HoodAF.Integrating Outpatient Teledermatology Education Into the Dermatology Resident Curriculum. J Grad Med Educ. 2016; 8(3): 468-9. https://doi. org/10.4300/JGME-D-15-00792.1 